\title{
A survey of the use of operational research in decisions made by micro, small and medium-sized enterprises in Macedonia
}

\author{
Violeta Cvetkoska ${ }^{1, \dagger}$ \\ ${ }^{1}$ Faculty of Economics - Skopje, Ss. Cyril and Methodius University in Skopje, Blvd. \\ Goce Delchev 9V, 1000 Skopje, Republic of Macedonia \\ E-mail: 〈vcvetkoska@eccf.ukim.edu.mk〉
}

\begin{abstract}
We live in a complex world and managers of organizations are constantly facing numerous challenges. Good decisions, i.e., better outcomes for organizations, require use of the powerful discipline Operational Research (OR)/Management Science (MS). Organizations applying this discipline have achieved significant benefits such as cost reduction, increased revenues, increased market share, higher quality, improved productivity, improved performance, better customer service, etc. The aim of this paper is to examine whether managers of micro, small and medium-sized enterprises in Macedonia use OR models for supporting decision-making processes, where OR models, methods and techniques are commonly used, and what benefits achieved in using quantitative OR models, methods and techniques. The survey was conducted using a questionnaire distributed electronically to 100 managers of micro, 100 managers of small and 100 managers of medium-sized enterprises. The questionnaires were answered completely by 93 managers of the micro, 73 managers of the small and 71 managers of the medium-sized enterprises, and the questionnaire responses were subsequently analyzed. The answers showed that decisions on running enterprises are made intuitively by $90 \%$ of managers of the micro, $78 \%$ of managers of the small, and $55 \%$ of managers of the medium-sized enterprises, while quantitative OR models for supporting the decision-making process are used by $10 \%$ of managers of the micro, $22 \%$ of managers of the small, and $45 \%$ of managers of the medium-sized enterprises. Applied in the micro, small and medium-sized enterprises are inventory models, time series analysis and forecasting, whereas micro and mediumsized enterprises rely on decision analysis. Small and medium-sized enterprises use breakeven analysis, assignation, linear programming, and project management. The OR models and methods used in running the respective enterprises led to the following results: optimal inventory level, cost reductions, revenue growth, forecasted sales, increased sales, production optimization, improved quality, better planning of activities, more efficient allocation of staff, absence of complaints and increased customers satisfaction.
\end{abstract}

Keywords: decision making, managers, operational research, micro enterprises, small enterprises, medium-sized enterprises

Received: September 25, 2016; accepted: December 15, 2016; available online: December 30,2016

DOI: $10.17535 /$ crorr. 2016.0024

\footnotetext{
$\dagger$ Corresponding author 


\section{Introduction}

Organization managers eventually become decision makers. Making the right decision leads to the organization's success, whereas wrong decisions lead to failure, and in the worst case, to disintegration of the organization. Making decisions under various forms of pressure, such as strong competition, increasingly demanding clients who seek lower prices, rapid technological changes, limited resources and time constraints, is not easily resolved. Hence, many organizations use Operational Research (OR) or Management Science (MS) to improve decision making. This discipline applies appropriate analytical methods to help organization managers make better decisions [8]. The OR/MS/quantitative analysis approach consists of the following steps [21, p. 23]: defining the problem, developing a model, acquiring input data, developing a solution, testing the solution, analyzing the results, and implementing the results. For more information on the OR, its approach, models and methods and their application, see: $[1,2,3,4,9,10,11,12,14,18,19,20,21,23,24,25,26]$. Some of the decision making areas where the science of operational research/management is applied are [2, pp. 5-8]: assignment, data mining, financial decision making, forecasting, logistics, marketing, networks, optimization, project planning and management, queuing, simulation, transportation, etc.

Operational research methods may be applied to solve real complex problems in various areas, such as agriculture, aviation industry, education, environmental and energy issues, finance, healthcare, logistics, marketing, military, mining industry, production management, transport, sport, supply chain management, telecommunications and information technology, etc.

Magee in [15] presents the application of operations research in marketing and related management problems. Datta and Bandyopadhyay in [6] studied the application of operational research in solving problems in industry and industrialization in developed countries. Approximately 230 articles have been published on this topic over the last two decades. Board, Sutcliffe and Ziemba in [5] examine the application of operations research techniques in financial markets. Semini in [22] examines the applicability of operations research in the management of material and information flows in manufacturing companies, i.e. in manufacturing logistics. Fakhimi and Probert [7] gave a review of operations research studies applied to healthcare. They limited the review with studies undertaken in UK which have been published since 2000. The analysis sample consisted of 142 high-quality journal and conference papers from the ISI Web of Knowledge data base. They found an interesting use of OR techniques in the UK healthcare system, and in the majority of studies, simulation was used.

The focus of this paper is empirical research on application of OR in micro, small and medium-sized enterprises in Macedonia. Therefore, the following research questions are posed: 1) Have managers of micro, small and medium-sized 
enterprises in Macedonia gained knowledge of operational research models and methods during their formal education, ongoing training or seminars? 2) Which of the OR models and methods have these managers acquired knowledge about during their formal education, ongoing training or seminars? 3) Do these managers apply OR models for supporting the decision-making process and what are the benefits for their enterprises? 4) Do these managers believe that students should study OR models and methods at all level of study at faculties of economics? 5) Are quantitative analysts hired as consultants in micro, small and medium-sized enterprises and if so, what has been the outcome?

We have found two studies in existing literature dealing with the use OR in companies, including other aspects.

Lonnstedt in [13] examined the use of operational research in twelve companies. Interviews were conducted with operational researchers and users. The obtained results identified the most common areas of use, specifically, coordination and production problems. Simulation and network planning were often used. Moreover, results indicated that if a company is divided into five levels, then most OR and its associated users are located at the third level.

Nikolic, Savic and Jovanovic in [17] examined the degree to which quantitative methods are used in management in Serbian companies. The authors referred to methods involving strategic planning (SWOT analysis, portfolio analysis, ABC analysis ...), formal decision-making methods (ELECTRE, PROMETHEE, AHP, TOPSIS, VICOR ...), and operational research methods (linear programing, transportation problems, network planning techniques, supply management, just to name a few). Thirty senior managers were asked to answer 12 questions. The research was conducted over a period of three months, from 1 September to 1 December). The respondents come mostly from very and average successful companies. According to the obtained results, the degree to management in Serbian companies uses quantitative methods is average. OR methods are used more often than strategic planning and formal decision-making methods. Managers of Serbian companies mostly use experience in solving problems. The main issues in the use of quantitative methods at management levels in Serbian companies are time constraints and lack of knowledge. Quantitative methods are most often use in sales, procurement, planning and analysis, as well as production preparation, and least often used in warehousing, public relations, human resource management, and strategic management. The level of knowledge on quantitative methods for management can be raised through courses and seminars for employees. Quantitative methods should occupy an important place in the education of managers (especially at the undergraduate and the master management studies).

The originality of our scientific contribution is that the analysis of using operational research in making decisions in micro, small, and medium-sized enterprises has been conducted for the first time in Macedonia. 
The introduction is given in Section 1, with the research methodology presented in Section 2. Next, Section 3 analyzes the results obtained from the examined micro, small and medium-sized enterprises in Macedonia, with a conclusion provided in Section 4.

\section{Research methodology}

To obtain answers to the research questions, a questionnaire containing a total of 21 questions was created. The target group of the survey were the managers of the micro, small and medium-sized enterprises in Macedonia, which belong to different industries. Besides the questions regarding sex, age and educational level, information about the location of the enterprises, business and employee numbers was obtained from the questionnaire. The questions that followed related as to whether the managers acquired knowledge about operational research models and methods during their formal education, and whether they attended training or seminars on operational research. If questions were answered affirmatively, the respondents would then state whether they acquired knowledge during their formal education, ongoing training, or at seminars on the following topics: breakeven analysis, probability and probability distribution, decision analysis, game theory, regression analysis, time series analysis and forecasting, inventory models, linear programing, transportation models, assignment, integer programing, goal programing, non-linear programing, dynamic programing, project management, waiting line models, simulation, Markov processes and multi-criteria decision making. This provided a conclusion from the subsequent questions as to whether the managers use quantitative factors, qualitative factors, or both, in solving problems they encounter in their enterprises, and how they make decisions (intuitively or using quantitative models that support decision making), as well as which OR models and methods they apply, and the specific benefits for the enterprise. The following questions examine whether the enterprise has employees who work with the construction of OR models and if so, how many are they. It is also examined if the employee who has constructed an OR model which helped in solving a problem, was rewarded. The last questions are whether students at all study levels of study at faculties of economics should study OR models and methods, whether enterprises hired a quantitative analyst for solving certain problems that arose in the enterprise and what the outcome was, and whether they plan to hire a quantitative analyst in the future. Finally, the respondents were asked to provide suggestions and comments.

The survey was conducted using a questionnaire that was sent in February 2016 by email to 100 managers of micro, 100 managers of small and 100 managers of medium-sized enterprises in Macedonia, and were given two weeks to complete it and send it back to the author of this paper. 


\section{Analysis of results}

\subsection{Analysis of the results from micro enterprises}

The questionnaire was answered completely by 93 respondents. The answers from these questionnaires were analyzed in a specific way.

Approximately $52 \%$ of the micro enterprises (48 enterprises) of the sample are located in Skopje, with 4 enterprises each located in: Bitola, Gostivar and Kocani, 3 enterprises each located in: Gevgelija, Kavadarci, Kicevo and Veles, 2 enterprises each located in: Negotino, Radovish, Struga, Strumica and Stip, and 1 enterprise each located in: Berovo, Valandovo, Vinica, Demir Kapija, Kumanovo, Makedonski Brod, Mavrovo, Pehcevo, Prilep, Strumica and Tetovo. According to the Macedonian National Classification of Activities NKD-Rev. 2, business activities are classified into sectors, departments, groups, classes and subclasses, which comprises 21 sectors, 88 departments, 272 groups, 615 classes and 4 subclasses [16]. According to the classification, most of the micro enterprises (46 enterprises or $49 \%$ of the sample) are involved in wholesale and retail trade, 10 enterprises (11\%) belong to the manufacturing industry, and 9 enterprises $(10 \%)$ are involved professional, scientific and technical activities.

Approximately $56 \%$ of the respondents (52 respondents) are male, whereas $44 \%$ of the respondents (41 respondents) are female. The average age of the respondents is 42 years of age.

In regards to the level of education, 43 respondents have a tertiary education, 33 have a secondary education, 12 have a short-cycle tertiary education, 4 respondents have a master's degree, and 1 respondent holds a doctorate degree. A total of $57 \%$ of the respondents (53 respondents) have acquired knowledge of operational research models and methods of, whereas $43 \%$ of the respondents (40 respondents) have not. In all, $76 \%$ of the respondents (71 respondents) have attended course or seminar for operational research models and methods, whereas $24 \%$ of the respondents (22 respondents) have not. Table 1 shows which OR models, methods and techniques the respondents have mastered during their formal education, or have attended a course or seminar. Most of the respondents in their formal education have acquired knowledge on break-even analysis (29 respondents), inventory models (22 respondents) and decision analysis (18 respondents), etc. In all, 5 respondents have attended courses on inventory and transportation models, but no one has attended a course on dynamic programing and waiting line models, however 4 respondents have attended seminars on assignment and project management. 


\begin{tabular}{|l|r|r|r|}
\hline \multicolumn{1}{|c|}{$\begin{array}{c}\text { Models, Methods, Techniques } \\
\text { of OR }\end{array}$} & $\begin{array}{c}\text { Formal } \\
\text { Education }\end{array}$ & Training & Seminar \\
\hline Break-Even Analysis & 29 & 3 & 3 \\
\hline Probability and Probability & 16 & 3 & 2 \\
Distributions & 18 & 3 & 3 \\
\hline Decision Analysis & 9 & 1 & 2 \\
\hline Game Theory & 5 & 2 & 2 \\
\hline Regression Analysis & 14 & & \\
\hline Time Series Analysis and & 22 & 2 & 1 \\
Forecasting & 7 & 5 & 2 \\
\hline Inventory Models & 4 & 3 & 1 \\
\hline Linear Programing & 10 & 2 & 2 \\
\hline Transportation Models & 6 & 1 & 4 \\
\hline Assignment & 5 & 1 & 2 \\
\hline Integer Programing & 4 & 2 & 2 \\
\hline Goal Programing & 3 & $/$ & 2 \\
\hline Nonlinear Programing & 9 & 3 & 4 \\
\hline Dynamic Programing & 8 & $/$ & 2 \\
\hline Project Management & 9 & 2 & 3 \\
\hline Waiting Line Models & 4 & 1 & 1 \\
\hline Simulation & 9 & 4 & 2 \\
\hline Markov Processes & & & \\
\hline Multi-Criteria Decision Making & & & \\
\hline
\end{tabular}

Table 1: OR models, methods and techniques which the respondents from micro enterprises have gained knowledge about during their formal education, or by attending training or seminars

When solving problems in their enterprises, $22 \%$ of the respondents (20 respondents) have considered qualitative factors, and $3 \%$ of the respondents (3 respondents) have considered quantitative factors, whereas $75 \%$ of the respondents (70 respondents) have considered both qualitative and quantitative factors.

In all, $90 \%$ of the respondents (84 respondents) have made decisions relating to business intuitively, while $10 \%$ of the respondents (9 respondents) have used quantitative models for supporting decision making. Of these 9 respondents, 4 have used decision analysis, 2 respondents have each applied inventory models and time series analysis and forecasting, and 1 respondent has used waiting line models. A total of 3 respondents from those who use the quantitative models as 
support in decision-making answered that the gained solution is implemented in the enterprise, which contributed to: finding an optimal level of inventory, cost reduction and prediction of the oscillations of the expected income.

Approximately $5 \%$ of the respondents (5 respondents) answered that they have an employee who works on constructing operational research models, 4 respondents answered that they each have 1 such employee in their enterprise, and 1 respondent answered having 3 personnel doing that particular job. The employees who have considerable quantitative skills and constructed a quantitative model of OR for a certain problem which resulted in certain benefits to the enterprise, should be rewarded according to the oppinion of five respondents. Regarding the type of the reward that should be appropriate, four out of fiverespondents stated a salary raise, whereas one respondent suggested a trip and a promotion in front of the other employees in the enterprise, emphasizing this employee as a role model to look up to.

A total of $87 \%$ of the respondents ( 81 respondents) believe that students should study operational research models and methods throughout their study (at the bachelor, masters and doctorate level) while study economics at university, whereas $13 \%$ of the respondents (12 respondents) think that studying operational research models and methods is not necessary.

Approximately $98 \%$ of the respondents (91 respondents) answered that they have not hired a qualitative analyst consultant, while $2 \%$ of the respondents (2 respondents) answered that they have and subsequently reduced costs.

In all, $48 \%$ of the respondents ( 45 respondents) answered that they plan to hire a quantitative analyst consultant in the near future, whereas $52 \%$ of the respondents (48 respondents) have no such plans.

The following is a list of comments and suggestions provided by some respondents from the micro enterprises:

- We want to use OR models and methods, but we don't have the appropriate knowledge.

- If possible for the enterprise, a good idea would be to provide training on OR models and methods for some of the employees, and use the gained knowledge for producing better results.

- Management should use the OR models and methods as it improve work in the enterprise (3 respondents).

- We want to hire a quantitative analyst consultant and cope better with future problems (4 respondents).

- Limited finances prevent us from hiring a quantitative analyst consultant.

- Economics at universities should focus on quantitative OR models so that students acquire a certain level of quantitative skills, which will help them make decisions in practical work (2 respondents). 
- I believe that operational research should be taken seriously, especially in the Bachelor of Arts studies at the faculties of economics as it would reduce costs, increasing profit, and help further developing the enterprise.

\subsection{Analysis of the results from small enterprises}

In all, 73 respondents answered the questionnaire in full. Their answers are analyzed below.

Approximately 41\% (38) of the small-sized enterprises are located in Skopje; 5 enterprises are located in Kavadarci; 8 enterprises with 4 located in each of the following locations: Bitola and Struga; 16 enterprises with 2 located in each of the following locations: Vinica, Kocani, Kriva Palanka, Negotino, Prilep, Radovish and Tetovo; and 9 enterprises, each located in following locations: Veles, Gevgelija, Demir Kapija, Krushevo, Kumanovo, Ohrid, Strumica and Shtip.

According to the Macedonian National Classification of Activities NKD-Rev. 2, most of the small enterprises (22 enterprises or 30\%) come from the manufacturing industry, 19 enterprises (26\%) are involved in wholesale and retail trade, and 7 enterprises (10\%) are involved in professional, scientific and technical services.

In all, $68 \%$ of the respondents (50 respondents) are male, while $32 \%$ of the respondents (23 respondents) are female. The average age of the respondents is 42 .

Regarding the level of education, 49 respondents have a tertiary degree, 21 respondents have completed secondary schooling, 2 respondents have a master's degree and 1 respondent holds a doctorate degree.

Approximately $52 \%$ of the respondents (38 respondents) have not acquired knowledge of the OR models and methods during their formal education, whereas $48 \%$ of the respondents (35 respondents) have gained such knowledge. A total of $73 \%$ of the respondents (53 respondents) have not attended training or a seminar on the OR models and methods, whereas $27 \%$ of the respondents (20 respondents) have attended a training or seminar. Table 2 shows which OR models, methods and techniques the respondents have gained knowledge of during their formal education and the relevant training or seminars. During their formal education, most of the respondents gained knowledge of break-even analysis (23 respondents), probability and probability distribution (18 respondents), decision analysis (16 respondents), etc. In all, 10 respondents have been trained in decision analysis and inventory models, and 8 respondents have attended a linear programing seminar. 


\begin{tabular}{|l|r|r|r|}
\hline \multicolumn{1}{|c|}{$\begin{array}{c}\text { Models, Methods, Techniques } \\
\text { of OR }\end{array}$} & $\begin{array}{c}\text { Formal } \\
\text { Education }\end{array}$ & Training & Seminar \\
\hline Break-Even Analysis & 23 & 6 & 7 \\
\hline Probability and Probability & 18 & 6 & 7 \\
Distributions & 16 & 10 & 4 \\
\hline Decision Analysis & 12 & 6 & 4 \\
\hline Game Theory & 11 & 6 & 2 \\
\hline Regression Analysis & 15 & & \\
\hline Time Series Analysis and & 11 & 6 & 5 \\
Forecasting & 9 & 4 & 3 \\
\hline Inventory Models & 8 & 7 & 8 \\
\hline Linear Programing & 10 & 5 & 5 \\
\hline Transportation Models & 9 & 4 & 2 \\
\hline Assignment & 8 & 3 & 3 \\
\hline Integer Programing & 7 & 4 & 3 \\
\hline Goal Programing & 9 & 4 & 4 \\
\hline Nonlinear Programing & 12 & 7 & 6 \\
\hline Dynamic Programing & 6 & 4 & 4 \\
\hline Project Management & 12 & 2 & 4 \\
\hline Waiting Line Models & 8 & 3 & 2 \\
\hline Simulation & 9 & 5 & 3 \\
\hline Markov Processes & & & 3 \\
\hline Multi-Criteria Decision Making & & & 4 \\
\hline
\end{tabular}

Table 2: OR models, methods and techniques for which the respondents from the small enterprises have gained knowledge during their formal education, training, or at seminars

In solving problems faced by the enterprise, $22 \%$ of the respondents (16 respondents) considered qualitative factors, $8 \%$ of the respondents (6 respondents) considered quantitative factors, while $70 \%$ of the respondents (51 respondents) addressed both qualitative and quantitative factors.

In all, $78 \%$ of the respondents ( 57 respondents) make intuitive business decisions, while $22 \%$ of the respondents ( 16 respondents) use quantitative models in decision making. Of these 16 respondents, 4 have applied break-even analysis in the past, whereas 2 respondents each have applied inventory models, time series analysis and forecasting, regression analysis, linear programming, project management and assignment. A total of 12 of those who use quantitative models in decision-making answered that acquired solutions have been implemented in their enterprises, resulting in cost reductions, covering of costs and sales growth (2 respondents each), forecasting of sales, product optimization, increased exports, improved 
customer satisfaction, revenue growth and efficient allocation of employees (1 respondent each).

A total of $10 \%$ of the respondents (7 respondents) answered that they have an employee at their disposal who works on constructing operational research models, 4 respondents answered that they each have 1 such employee in their enterprise, 2 respondents answered that they have 2 such employees in their enterprises, and 1 respondent answered that the number of such employees in their enterprise totals 5. According to four our of five respondents, the employees with a considerable level of quantitative skills who constructed quantitative model for a certain problem which resulted in a certain benefit to the enterprise, should be rewarded with a salary raise. However, $90 \%$ of the respondents answered that there are no employees who work with the construction of OR models in their enterprise.

In all, $88 \%$ of the respondents (64 respondents) believe that students should study OR models and methods in their university courses (at the bachelor, master's and doctorate level), whereas $12 \%$ of the respondents (9 respondents) said that there was no need to study OR models and methods.

A total of $84 \%$ of the respondents (61 respondents) answered that they have not hired a quantitative analyst consultant in the enterprise, whereas $16 \%$ of the respondents (12 respondents) answered that they have hired such a consultant and subsequently achieved: cost reductions (6 respondents), revenue growth (4 respondents) and have been able to determine the break-even point (2 respondents).

In all, $67 \%$ of the respondents (49 respondents) answered that they plan to hire a quantitative analyst consultant in the future, whereas $33 \%$ of the respondents (24 respondents) have not such plans.

The following is a list of the comments and suggestions given by some of the respondents from the small enterprises:

- Increased changes on the market also increase the need for implementing OR models and methods in enterprise operations.

- The OR models and methods should be used in enterprise operations in order to achieve better efficiency, higher income and reduced costs.

- Training in the OR models and methods should be offered to the managers in enterprises (2 respondents).

- If financially possible, a group of employees should be trained in OR models and methods.

- A good idea is to get economics students to study OR models and methods at university in order to better respond to the numerous problems encountered by enterprises (2 respondents).

- Young people who are familiar with OR models and methods should endeavor to apply them in enterprises. 
- A good idea is for every enterprise to have an OR quantitative analyst consultant or hire one to achieve better business results in the enterprise (4 respondents).

\subsection{Analysis of the results from medium-sized enterprises}

The questionnaire was fully answered by 71 respondents, and the answers from these questionnaires are analyzed below.

In all, $55 \%$ of the medium-sized enterprises (39 enterprises) that constitute the analysis sample are located in Skopje, 4 enterprises are located in Kavadarci, 3 enterprises each are located in Kumanovo and Bitola, 2 enterprises each are located in Gostivar, Delcevo, Kocani, Prilep, Struga, Tetovo and Shtip, and 1 enterprise each in Gevgelija, Demir Hisar, Veles, Vinica, Kriva Palanka, Ohrid, Sv. Nikole and Strumica.

According to the Macedonian National Classification of Activities NKD-Rev. 2, most enterprises (27 enterprises, or $38 \%$ of the enterprises) belong to the manufacturing industry, 16 enterprises $(23 \%)$ are involved in wholesale and retail trade, and 10 enterprises (14\%) come from the construction industry.

Approximately $51 \%$ of the respondents (36 respondents) are male, while $49 \%$ of the respondents (35 respondents) are female. The average age of the respondents is 43 years of age.

In regard to the level of education, 50 respondents have a tertiary education, 10 respondents have a secondary education, 6 respondents have a master's degree and 5 respondents have received a short-cycle tertiary education.

In all, $61 \%$ of the respondents (43 respondents) have developed skills in operational research models and methods during their formal education, while $39 \%$ of the respondents (28 respondents) have not. Approximately $37 \%$ of the respondents (26 respondents) have attended training or seminars on OR models and methods, and $63 \%$ of the respondents ( 45 respondents) have not. During their formal education, most respondents have acquired knowledge of break-even analysis (32 respondents), decision analysis (24 respondents), probability and probability distribution (22 respondents), etc. In all, each of the 9 respondents have attended training on decision analysis, inventory models and project management, 8 respondents have attended training on time series analysis and forecasting, whereas each of the 9 respondents have attended seminars on breakeven analysis and project management, each of the 8 respondents have attended seminars on decision analysis and inventory models., but no one has attended seminars on linear programing. 


\begin{tabular}{|l|r|r|r|}
\hline \multicolumn{1}{|c|}{$\begin{array}{c}\text { Models, Methods, Techniques } \\
\text { of OR }\end{array}$} & $\begin{array}{c}\text { Formal } \\
\text { Education }\end{array}$ & Training & Seminar \\
\hline Break-Even Analysis & 32 & 7 & 9 \\
\hline Probability and Probability & 22 & 7 & 3 \\
Distributions & 24 & 9 & 8 \\
\hline Decision Analysis & 10 & 6 & 4 \\
\hline Game Theory & 6 & 3 & 4 \\
\hline Regression Analysis & 15 & & \\
\hline Time Series Analysis and & 18 & 8 & 5 \\
Forecasting & 14 & 9 & 8 \\
\hline Inventory Models & 9 & 4 & $/$ \\
\hline Linear Programing & 6 & 3 & 5 \\
\hline Transportation Models & 8 & 3 & 1 \\
\hline Assignment & 8 & 1 & 2 \\
\hline Integer Programing & 8 & 1 & 3 \\
\hline Goal Programing & 6 & 1 & 2 \\
\hline Nonlinear Programing & 18 & 2 & 2 \\
\hline Dynamic Programing & 5 & 9 & 9 \\
\hline Project Management & 9 & 5 & 5 \\
\hline Waiting Line Models & 5 & 5 & 2 \\
\hline Simulation & 13 & 3 & \\
\hline Markov Processes & & 3 & 7 \\
\hline Multi-Criteria Decision Making & & & \\
\hline
\end{tabular}

Table 3: OR models, methods and techniques for which the respondents from mediumsized enterprises gained knowledge during their formal education, training, or by attending seminars

When solving the problems in their enterprises, $14 \%$ of the respondents (10 respondents) take into consideration qualitative factors, $6 \%$ of the respondents (4 respondents) consider quantitative factors, while $80 \%$ of the respondents ( 57 respondents) take both the qualitative and quantitative factors into consideration. In all, $55 \%$ of the respondents (39 respondents) make decisions on enterprise decisions intuitively, while $45 \%$ of the respondents (32 respondents) use quantitative models in their decision making. Most of these 32 respondents used the break-even analysis (11), follow by project management (5), inventory models (4), time series analysis and forecasting (4), decision analysis (3), assignment (2), game theory (1), linear programing (1) and multi-criteria decision making (1). A total of 15 respondents who use quantitative models in decision making answered that the solution they acquire is implemented in the enterprise, and contributed to increase in sales (4 respondents), cost reductions and improved activity 
planning (3 respondents each), forecasting of sales and improved quality (2 respondents each) as well as an absence of complaints (1 respondents).

A total of $20 \%$ of the respondents (14 respondents) answered that they have employed someone who works on constructing OR models (half of them answered that they each have 1 employee doing this kind of job). According to 9 respondents the employees with a considerable level of quantitative skills who created a quantitative model for a certain problem which resulted in a certain benefit to the enterprise, should be rewarded with a cash reward (according to 7 respondents), and a salary raise or a bonus (1 respondent each). In all, $80 \%$ of the respondents (57 respondents) answered that they have not employed someone to work on constructing operational research models.

In all, $92 \%$ of the respondents (65 respondents) believe that students should study OR models and methods at all levels of study (bachelor, master's and doctorate level), while $8 \%$ of the respondents (6 respondents) said that there is no need to study OR models and methods.

A total of $14 \%$ of the respondents (10 respondents) answered that they have hired a quantitative analyst consultant, and subsequently achieved cost reductions (3 respondents), revenue growth (2 respondents), improved productivity, improved quality, reduced customer complaints, better forecasting of potential gain and loss, and optimization of supply processes in opening a new restaurant (1 respondent each), whereas $86 \%$ of the respondents (61 respondents) answered that they have not hired a qualitative analyst consultant.

In all, $69 \%$ of the respondents (49 respondents) answered that they plan to hire a qualitative analyst consultant in the future, whereas $31 \%$ of the respondents (22 respondents) have no such plans.

The following is a list of the comments and suggestions given by some of the respondents from the medium-sized enterprises:

- OR models and methods will help in improving decisions within their enterprises.

- OR models save time and money.

- The use of quantitative models and methods for prediction is exceptionally important for demand and possible risks.

- Operational research is very important to those who have decided to work autonomously on projects and businesses (entrepreneurs, farmers). Farmers often fail to achieve profits because they have no knowledge of this discipline. Hence, they should receive training as a precondition for obtaining any kind of state support.

- OR models and methods are used often in many companies abroad, and the personnel that have mastered such skills are in demand in enterprises in our country. 
- A managers' failure to understand OR and its application is a huge disadvantage. Enterprises achieve greater success if managers are familiar with OR models and methods.

- Enterprises should employ a quantitative analyst for greater success.

- OR is a very significant applicative discipline, studied at all prestigious universities in the world. The respective models and methods are applied in numerous renowned and successful companies.

\section{Discussion and conclusion}

The field of operational research offers a range of models, methods and techniques that can assist managers in making better decisions in organizations. The wide scope of this discipline in the world is due to its benefits such as cost reductions, revenue growth, improved quality, improved performance, increased productivity. Also, information technology contributed the development of operational research by providing a large number of software tools that enable usage of OR models and methods.

This paper covers research on managers from micro, small and medium-sized enterprises in Macedonia that belong to different industries and answers have been obtained from the managers for specific survey questions.

For the first survey question, $57 \%$ of the respondents from micro enterprises, $48 \%$ of the respondents from small enterprises and $61 \%$ of the respondents from medium-sized enterprises have acquired some knowledge of operational research models and methods during their formal education, whereas $76 \%$ of the respondents from micro enterprises, $27 \%$ of the respondents from small enterprises and $37 \%$ of the respondents from medium-sized enterprises have attended training or seminars on OR models and methods.

Based on received answers to the second survey question, the conclusion is that most of the respondents from micro, small and medium-sized enterprises have acquired knowledge of the break-even analysis during their formal education, including training in inventory models, while most of the respondents from micro and medium-sized enterprises have gained some knowledge of project management at seminars, as well as those respondents from small enterprises in linear programming.

Concerning answers to the third survey question, the conclusion is that most of the respondents from micro, small and medium-sized enterprises make decisions intuitively. Further, $10 \%$ of the respondents that come from micro enterprises, $22 \%$ from small enterprises and $45 \%$ from the medium-sized enterprises also used quantitative models in decision making. Inventory models and time series analysis and forecasting are used in the micro, small and medium-sized enterprises. In addition, decision analysis is used in micro and medium-sized enterprises. Breakeven analysis, assignment, linear programing and project management are used in 
small and medium-sized enterprises. The benefits achieved in using quantitative models in decision making are cost reductions, successful coverage of costs, revenue growth, the forecasting of sales, predicting fluctuations in expected income, increased exports, production optimization, determining the optimal inventory level, better planning of activities, more efficient allocation of staff, reduction of customer complaints and improved customer satisfaction.

Regarding the fourth survey question, most of the respondents $(87 \%$ of the respondents from micro enterprises, $88 \%$ from small and $92 \%$ from the mediumsized enterprises) believe that students should study operational research models and methods at all levels of study (bachelor master's and doctorate level) at the faculties of economics.

Answers to the fifth survey question indicated that most of the respondents have not hired a quantitative analyst consultant for solving enterprise problems, while who answered that they have hired a quantitative analyst listed the following benefits: cost reductions, increased revenues, achieving the break-even point, increased productivity, improved quality, absence of complaints and optimization of the supply process in opening a new restaurant.

Certain conclusions based on the comments and suggestions from some of the respondents can be drawn. There is only a minimal number of managers familiar with the OR discipline and its use. Therefore, training in OR models, methods and techniques is desirable, which would enable the managers to acquire a certain level of knowledge to help them in making better decisions. The benefits of OR models and methods are cost reductions, increased revenues, efficiency increases, development of the enterprise. This discipline should be made mandatory for economics students in order that they acquire knowledge for use at work in enterprises.

\section{References}

[1] Albright, C., and Winston, W. L. (2016). Practical management science, revised $5^{\text {th }}$ ed. Boston: Cengage Learning.

[2] Anderson, D. R., Sweeny, D. J., Williams, T. A., Camm J. D., and Cochran, J. J. (2016). An Introduction to Management Science: Quantitative Approaches to Decision Making, $14^{\text {th }}$ ed. Boston: Cengage Learning.

[3] Anderson, D. R., Sweeny, D. J., Williams, T. A., Camm, J. D., Cochran J. J., and Fry M. J. (2013). Quantitative Methods for Business, $12^{\text {th }}$ ed. Mason: South-Western a part of Cengage Learning.

[4] Babic, Z. (2011): Models and Methods of Business Decision Making. Split: University in Split, Faculty of Economics Split. (On Croatian)

[5] Board, J., Sutcliffe, C. and Ziemba, W. T. (2003). Applying operations research techniques to financial markets. Interfaces, 33(2), 12-24. 
[6] Datta, S. and Bandyopadhyay, R. (1994). Applications of operational research in industry and industrialization in the developing countries: A Review, Omega, 22(2), 173-184.

[7] Fakhimi, M. and Probert, J. (2013). Operations research within UK healthcare: a review. Journal of Enterprise Information Management, 26(1/2), 21-49.

[8] For Operational Research. http://www.scienceofbetter.co.uk/about-or [Accessed 10/07/16].

[9] Goodwin, P., and Wright, G. (2014). Decision Analysis for Management Judgment, $5^{\text {th }}$ ed. Chichester: John Wiley \& Sons Ltd.

[10] Hillier, F. S., and Lieberman, G. J. (2014). Introduction to Operations Research, $10^{\text {th }}$ ed. New York: McGraw-Hill Education.

[11] Hillier, F.S., Hillier, M.S., Schmedders, K., and Stephens, M. (2014). Introduction to Management Science: A Modeling and Case Studies Approach with Spreadsheets, $5^{\text {th }}$ ed. New York: McGraw-Hill.

[12] Jensen, P. A., and Bard, J. F. (2003). Operations Research: Models and Methods, Hoboken: John Wiley \& Sons, Inc.

[13] Lonnstedt, L. (1973). The use of operational research in twelve companies quoted on the Stockholm Stock Exchange. Operational Research Quarterly, $24(4), 535-545$.

[14] Lukac, Z., and Neralic, L. (2012). Operacijska istraživanja (Operational Research), Zagreb: Element.

[15] Magee, J. F. (1954). Application of operations research to marketing and related management problems. Journal of Marketing, 18(4), 361.

[16] National Classification of Activities- NKD-Rev.2 (2013). http://www.stat.gov.mk/KlasifikaciiNomenklaturi.aspx?id=2 [Accessed 04/ $02 / 16]$.

[17] Nikolic, M., Savic, M., and Jovanovic, D. (2010). Implementation of quantitative methods in the management of serbian companies. Multiarts, 1(1), 3-9.

[18] Powell, S. G., and Baker, K. R. (2013). Management Science: The Art of Modeling with Spreadsheets, $4^{\text {th }}$ ed. Hoboken: Wiley.

[19] Rardin, R. L. (2016). Optimization in Operations Research, $2^{\text {nd }}$ ed. London: Pearson.

[20] Ravndran, A. R. (2008). Operations Research and Management Science Handbook. Boca Raton: CRC Press.

[21] Render, B., Stair, R. M. Jr., Hanna, M. E., and Hale, T. S. (2015). Quantitative Analysis for Management, $12^{\text {th }}$ ed. Harlow: Pearson Education Limited.

[22] Semini, M. (2011). Applicability of Operations Research in Manufacturing Logistics. Doctoral Thesis at NTNU, ISSN 1503-8181. http://www.divaportal.org/smash/get/diva2:477533/fulltext01.pdf [Accessed 01/09/2016] 
[23] Taha, H. A. (2016). Operations Research: An Introduction, 10 ${ }^{\text {th }}$ ed. London: Pearson.

[24] Taylor, B. W. III. (2016). Introduction to Management Science, 12 ${ }^{\text {th }}$ ed. Harlow: Pearson Education Limited.

[25] Todosioska, B. (2001). Management Science, Skopje: Faculty of EconomicsSkopje.

[26] Williams, T. (2008). Management Science in Practice, Chichester: John Wiley \& Sons, Ltd. 